\title{
One Health Paradigm: Review on the Challenges of Tackling Zoonotic Disease
}

Tekalign Tadesse and Endalu Mulatu*

Bedele College of Agriculture and Forestry, Mettu University, Mettu, Ethiopia

*Corresponding author: Endalu Mulatu, Bedele College of Agriculture and Forestry, Mettu University, Mettu, Ethiopia, Tel: +251-917-095-077; E-mail: indexbest2010@gmail.com

Received date: July 02, 2018; Accepted date: July 30, 2018; Published date: July 31, 2018

Copyright: @2018 Tadesse T, et al. This is an open-access article distributed under the terms of the Creative Commons Attribution License, which permits unrestricted use, distribution, and reproduction in any medium, provided the original author and source are credited.

\begin{abstract}
We are in the world of Explosive human population, expanding agricultural systems, intensification of livestock, changing macro and micro climate, increased global trade and urbanization which contributed to increased interactions between animals, humans and wildlife species, leading to the emergence and re-emergence of many zoonoses. Emerging and re-emerging of zoonotic diseases negatively affect a human and animal population. To tackle this problem, One Health approach has a great role, it needs strong collaborative efforts and interdisciplinary communication to prevent epidemic or epizootic diseases and to maintain ecosystem integrity thereby improving and defending optimal health of globe. Despite this potential, failure to work collaboratively, lack of awareness, absence of a standardized frame work to capture the concept of disciplines and other problems with difficulty of wildlife management had negative impact on one health implementation. By solving the challenges of one health approach; it is possible to make it more powerful tool to protect defend living things and the environment from diseases around the globe, therefore all concerned body should participate in the one health activity to achieve the future expected of one health approach.
\end{abstract}

Keywords: One health; Challenge; Collaboration; Zoonotic disease

\section{Introduction}

Animal and human medicine has no dividing lines- nor should there be. According to Rudolf Virchow, this recognition that human and animal health is linked is as important now as ever. More than $60 \%$ of pathogens that cause diseases in humans are zoonotic- diseases of animals that can infect people and among thus $75 \%$ of them are zoonotic as well [1]. Zoonotic diseases are diseases caused by all types of pathogenic/disease causing agents which are directly or indirectly transmitted from animals to humans and vice versa [2]. About 15 bacterial and viral zoonotic diseases were emerged in past few years. Thus includes Hanta, Ebola, highly pathogenic avian influenza (H5N1 and recently H7N9), West Nile, Rift Valley fever, norovirus, severe acute respiratory syndrome (SARS), Marburg, influenza A (H1N1), Escherichia coli O157, Plague, and Anthrax.

The emergences of zoonotic diseases were increasing. From 1980s until now, above 87 new zoonotic and/or vector-borne emerging infectious diseases (EIDs) have been identified. The global economic burden due to zoonotic diseases is very high. World Bank report revealed that, the economical impact of six zoonotic diseases outbreak that have occurred in some countries from $1997-2009$ is estimated to be US $\$ 80,000,000,000$ [3].

Humans are still evolving under the influence of health challenges which need: scientific advances, political, economic, environmental and professional priorities [4]. To overwhelm these problem "One World, One Health concept" was formulated by the Wildlife Conservation Society in 2004 and establishes an interdisciplinary and cross-sectorial approach to prevent epidemic or epizootic disease [5]. One health concept starts longtime ago in human history but becomes inaction and globally recognized as a major area of concern in recent years. It is majorly concerned with human, animal and environment interfaces. This integrated strategy gives a unique and significant opportunity for veterinary medicine to be in a leadership role and to work collaboratively for ecosystem health for the greater wellbeing of society [6].

In spite of all the struggles, there are significant challenges and hindering factors for application of the One Health program which are blamable to the less achievement of the one health paradigm. Therefore the ultimate purpose of this review is to collect and compile available literatures on challenges attributable to the inefficiency of the approach that should be addressed carefully in time to ensure the implementation of One Health concept there by setting some recommendation forth, that should be implemented by all concerned body at the grassroots level.

\section{Challenges of One Health Paradigm}

One health approach is getting world wide acceptance as strategic and holistic approach in combating global health problem which the connections between humans, animal and environment. In addition to this economic, cultural and physical factors that influence health also recognized by the approach [7]. The emerging and re-emerging diseases were driven by several factors. Thus includes genetic and biological factors (microbial adaptation to macro- and microenvironmental changes, changes in host susceptibility to infection), environmental factors (climatic change, ecosystems change and human and animal demography and densities changes) and socioeconomic and political factors (increasing international travel and trade, social inequality, poverty, famine, changes in economic development and land use). According to Institute of Medicine report, these factors were referred as driving forces for emergence of new zoonotic diseases 
and creates favorable condition for microbial population to be appeared [8].

\section{Problem of working collaboratively}

One Health approach should emphasize interdisciplinary collaboration, involving different disciplines both within and beyond the health sciences to address transnational health issues and solutions. One Health approach offers an even broader multi-systems perspective on health means and the inclusion of a wider range of expertise to include areas of academic specialization [9]. Conceptual and methodological differences between professionals of veterinary and human medicines are the most substantial challenges faced collaborative working across the globe [10]. Especially this challenge appears in determining the appropriate level of integration of different disciplinary methods and concepts, translating each discipline's terminology and concepts into the other participating and mediating different assumptions and views about what counts. As evidence, how it can be acquired and how it can be validated, incorporating stakeholder input in research topics and design, facilitating debates over objectivity versus social construction and combining preferences for reductionist or holistic approaches [11].

Scientific knowledge and technical achievement is more important for successfulness of One Health approach. To develop more holistic and diverse understandings of health across cultures, species, ecosystems and local communities there are a lot of global challenges [10]. This is not consistent with the goals of global health effort which stresses the value and necessity of seeking participation from local communities and building interventions that draw on the capacities and resources of those communities [12]. Clearly involving community members in health projects is essential for planning interventions which do not inadvertently have negative health effects due to a failure to take into account the complexity and specificity of local conditions. Engaging communities in land-use decisions and approaches to disease control should be part of an integrated One Health approach [13].

\section{Socio-political challenges}

Application of one health concept will be challenged with Sociopolitical issues because of people's belief and attachment with right and freedoms even though they cannot pay sacrifice for the concern of others. For this reason zoonotic disease control and prevention policy making depends on individual behavior than factors that drive disease emergence/re-emergence [14]. Egoism, perceptions, short term solutions, populism and avoiding argument are characteristics of politics, which result in challenges for emerging zoonotic disease prevention and control policy making and affect development of effective strategies for addressing EIDs [15].

Scientific evidence and societal perceptions proved that political intervention had role in zoonotic disease prevention and control. Indeed in the face of scientific uncertainty and ethical ambiguity, ideological perspectives and short-term political considerations often supplant efforts to devise effective long-term interventions [15]. In the case of zoonotic and EID powerful interests dominated early government responses, leading policy makers to make decisions that avoided public controversy but had major economic consequence [16].

\section{Ethical concern}

Effective zoonotic disease combating policy relays on its implementation context and especially on its alignment with stakeholder and public principles [17]. Like in modern liberalism there should be a few agreements over what is in the community interest and an understanding of the values which sustain it is required for the successful achievement of zoonotic disease prevention. However, this is in particular what has been missing in epidemics where fracture lines differences and value conflicts have become noticeable [15]. Other occurrence happen that stakes are high, evidence and the implications of actions are uncertain, the situation is complex and resources are limited but where decisions need to be made its ethical differences are exposed to challenge [18]. This discrepancy could be due to beliefs that deal with ecological and environmental issues can clashed with the significance of peoples connection to public goods, protection of individual and animal welfare [15]. This condition results adverse costs of public fear, doubt, misinformation and disobedience with public health directives [19].

Successful response of outbreaks in a One Health approach wants to address the above stated ethical concerns. To do this successful diverging values and logics must be negotiated to realize effective, sustainable and just solutions by considering the public interest as an apriority task [14].

\section{Legal challenges}

The legal frame work that made for control and prevention of EIDs has its own set of challenges [16]. The laws that govern disease outbreak control mechanism in most jurisdictions are scattered, confusing and interpreted based on interest individual whose idea is dominant at the time of decision making [15]. The other complication and confusion appears to the epidemic regulatory structures rather than facilitating public health responses to EID [20]. The cost of laws restricts development of greater global health inequities with consequential effects for health outcomes. In order to simplify EID related legal complications in between economic development and health security, additional precise and clear cut recognition is needed of who are the principal beneficiaries and who bears the expenses of EIDs [21].

\section{Challenges of managing wild life ecosystem}

The ecosystem changes due to driving forces can alter the state of well-being and leads change the interaction between human and animal population [8]. It is important to identify the routes by which the wild animal reservoirs agent found their way to the human host and their impact on the animals that serve as the primary and intermediate hosts [22]. It is intrinsically more difficult to monitor diseases in wildlife due to; afraid of aggressive wild animals, lack of knowledge and experience, inadequate financial recourse and lack of road. Wild animals are not constrained by boundaries and can extend over large distances. This is particularly for migratory birds or mammals which seasonally move across continents or vast oceans which they cause spreading of disease [18]. The declines and disappearances of different wild life species are due to disease of a certain pathogen. Practical difficulties can exist in determining the mortality rates because of dispersal after disease outbreak. It can also be difficult for many different reasons to find and count both sick and dead wild animals [22]. 
As zoonotic disease surveillance in wildlife clearly represents a great predictive modeling and known patterns in host range can be used to focus the effort on the species and pathogens that pose the greatest risk of zoonotic emergence. The surveillance and monitoring of disease outbreaks in wildlife populations are particularly relevant in these days of rapid human and animal translocation and the contact between wild and domestic animals is close and the threat of a bioterrorist attack is very real [16].

\section{Conclusion}

Health care issues of human is facing several problems that need world wide solutions for the prevention and control of the spread of emerging and re-emerging infectious diseases between animals, humans and the ecosystem. Globalization, human population increment and frustration with current health care method enforce the world to look for latest health care alternatives. One health is a means of effective control and prevention of zoonotic diseases. To implement one health one should consider all the components of it which are interacting each other. By solving the challenges of one health approach it is possible to make it more powerful tool for prevention and control of zoonotic diseases. Therefore to overcome challenges for application of one health there should be awareness creation on the approach and political commitment is needed.

\section{References}

1. Dahal R, Kahn L (2014) Zoonotic Diseases and One Health Approach Epidemiol 4: el15.

2. Peña A, Gomariz M, Lucio M, González-Torres P, Huertas-Cepa J, et al. (2014) Salinibacter ruber: the never ending microdiversity?. In: Papke T, Oren A, Ventosa A (eds). Halophiles: Genetics and Genomes. Caister Academic Press, pp: 37-53.

3. World Bank (2012) People, Pathogens and Our Planet. Volume 2. The Economics of One Health. World Bank Report \#69145 GLB. Washington (D.C): World Bank people pathogens-planet-economics-one-health. Accessed 6 October 2014.

4. Galaz V, Leach M, Scoones I, Stein C (2015) The political economy of one Health research and policy. Steps Working Paper 81 Brighton, Steps Centre Publications, UK, pp: 1-35.

5. Angesom HD (2016) One Health: An Integrated Approach for Disease Control in Pastoral Areas of Ethiopia. Journal of Health, Medicine and Nursing 22: 45-48.

6. Pal M (2005) Importance of zoonoses in public health. Indian Journal of Animal Sciences 75: 586-591.

7. Conrad PA, Meek LA, Dumit J (2013) Operationalizing a One Health approach to global health challenges. Comp Immunol Microbiol Infect Dis 36: 211-216.
8. Smolinski MS, Hamburg MA, Lederberg J (2003) Microbial Threats to Health: Emergence, Detection, and Response. National Academy Press, Washington (DC).

9. ICOPHAI (2011) First International Congress on Pathogens at the Human-Animal Interface (ICOPHAI). Addis Ababa, Ethiopia. Accessed on 6 October 2014.

10. Barlow J, Ewers R, Anderson L, Aragao L, Baker T (2011) Using learning networks to understand complex systems, a case study of biological, geophysical, and social research in the Amazon. Biol Rev Camb Philos Soc 86: 457-474.

11. Mayol E, Jiménez MA, Herndl GJ, Duarte CM, Arrieta JM (2014) Resolving the abundance and air-sea fluxes of airborne microorganisms in the North Atlantic Ocean. Front Microbiol 5: 557.

12. Koplan J, Bond T, Merson M, Reddy K, Rodriguez M, et al. (2009) Towards a common definition of global health. The Lancet 373: 1993-1995.

13. Anderson W (2004) Natural histories of infectious disease: ecological vision in 20th century biomedical science. Osiris 19: 39-61.

14. Rosella L, Wilson K, Crowcroft N, Chu A, Upshur R (2013) Pandemic H1N1 in Canada and the use of evidence in developing public health policy analysis. Soc Sci Med 83: 1-9.

15. Degeling C, Johnson J, Kerridge I, Wilson A, Ward M, et al. (2015) Implementing One Health Approach to Emerging Infectious Disease, Reflections on the socio-political, ethical and legal dimensions. BMC Public Health 15: 1307.

16. Zinsstag J, Schelling E, David W, Maxine W, Tanner M (2014) One Health the Theory and Practice of Integrated Health Approaches. pp: 23-130.

17. Mackenzie S, Jeggo M, Daszak P, Juergen A (2013) One Health, The Human- Animal-Environment Interfaces in Emerging Infectious Diseases. Current Topics in Microbiology and Immunology 365: 1-340.

18. Singer P, Benatar S, Bernstein M, Daar A, Dickens BM, et al. (2003) Ethics and SARS: lessons from Toronto. British Medical Journal 327: 1342-1344.

19. Davies $S$ (2010) What contribution can international relations make to the evolving global health agenda?. Int Aff 86: 43-65.

20. CDC (2010) Operationalizing —one health: A policy perspective taking stock and shaping an implementation roadmap. Stone Mountain, Georgia, pp: 1-24.

21. Mörner T, Obendorf L, Artois M, Woodford M (2002) Surveillance and monitoring of wildlife diseases. Rev Sci Tech 21: 67-76.

22. Jackson S (2015) Economic Benefits of a One Health approach. The World Bank, Report No: ICR00003260, Implementation Completion and Results Report on the European Commission Avian and Human Influenza Trust Fund (EC-AHI), p: 2. 